\title{
Calpain-2-Mediated PTEN Degradation Contributes to BDNF-Induced Stimulation of Dendritic Protein Synthesis
}

\author{
Victor Briz, ${ }^{1 \star}$ Yu-Tien Hsu, ${ }^{3 *}$ Yi Li, $^{1}$ Erin Lee, ${ }^{3}$ Xiaoning Bi, ${ }^{2}$ and Michel Baudry ${ }^{1,3}$ \\ ${ }^{1}$ Graduate College of Biomedical Sciences and ${ }^{2}$ Basic Medical Sciences College of Osteopathic Medicine of the Pacific, Western University of Health Sciences, \\ Pomona, California 91766, and ${ }^{3}$ Department of Biological Sciences, University of Southern California, Los Angeles, California 90089
}

\begin{abstract}
Memory consolidation has been suggested to be protein synthesis dependent. Previous data indicate that BDNF-induced dendritic protein synthesis is a key event in memory formation through activation of the mammalian target of rapamycin (mTOR) pathway. BDNF also activates calpain, a calcium-dependent cysteine protease, which has been shown to play a critical role in learning and memory. This study was therefore directed at testing the hypothesis that calpain activity is required for BDNF-stimulated local protein synthesis, and at identifying the underlying molecular mechanism. In rat hippocampal slices, cortical synaptoneurosomes, and cultured neurons, BDNFinduced mTOR pathway activation and protein translation were blocked by calpain inhibition. BDNF treatment rapidly reduced levels of hamartin and tuberin, negative regulators of mTOR, in a calpain-dependent manner. Treatment of brain homogenates with purified calpain-1 and calpain- 2 truncated both proteins. BDNF treatment increased phosphorylation of both Akt and ERK, but only the effect on Akt was blocked by calpain inhibition. Levels of phosphatase and tensin homolog deleted on chromosome 10 (PTEN), a phosphatase that inactivates Akt, were decreased following BDNF treatment, and calpain inhibition reversed this effect. Calpain-2, but not calpain-1, treatment of brain homogenates resulted in PTEN degradation. In cultured cortical neurons, knockdown of calpain-2, but not calpain-1, by small interfering RNA completely suppressed the effect of BDNF on mTOR activation. Our results reveal a critical role for calpain-2 in BDNF-induced mTOR signaling and dendritic protein synthesis via PTEN, hamartin, and tuberin degradation. This mechanism therefore provides a link between proteolysis and protein synthesis that might contribute to synaptic plasticity.
\end{abstract}

\section{Introduction}

Long-term potentiation (LTP) of synaptic transmission represents a long lasting increase in synaptic strength and is widely accepted as a physiological mechanism underlying memory formation in mammalian brain. Several molecular/cellular events participate in LTP induction/stabilization, including dendritic protein synthesis (Bramham, 2008) and calpain activation (Lynch and Baudry, 1987; Staubli et al., 1988; Oliver et al., 1989; Vanderklish et al., 1995, 1996). In particular, dendritic translation of a number of locally present mRNAs, including that for the activity-regulated cytoskeleton-associated protein (Arc), is important for both LTP consolidation and memory formation (Wells and Fallon, 2000; Pfeiffer and Huber, 2006; Bramham, 2007).

Calpains represent a unique family of calcium-dependent, neutral, cysteine proteases that play critical roles in different neuronal processes. Calpain activation results in the truncation of target proteins, leading to persistent modifications of their functions and in time-dependent changes in synaptic properties and

\footnotetext{
Received Oct. 18, 2012; revised Dec. 25, 2012; accepted Jan. 19, 2013.

Author contributions: V.B., Y.-T.H., X.B., and M.B. designed research; V.B., Y.-T.H., Y.L., and E.L. performed research; V.B., Y.-T.H., Y.L., E.L., X.B., and M.B. analyzed data; V.B., Y.-T.H., X.B., and M.B. wrote the paper.

This work was supported by NINDS Grant P01NS045260-01 (PI, Dr. C.M. Gall).

*V.B. and Y.-T.H. contributed equally to this work.

The authors declare no competing financial interests.

Correspondence should be addressed to Michel Baudry, NSC, Room 102C, Western University of Health Sciences, 309 East 2nd Street, Pomona, CA 91766-1854. E-mail: mbaudry@western.edu.

DOI:10.1523/JNEUROSCI.4907-12.2013

Copyright $\odot 2013$ the authors $\quad 0270-6474 / 13 / 334317-12 \$ 15.00 / 0$
}

functions. Specifically, calpain inhibitors or downregulation of calpain-2 block LTP induction both in hippocampal slices and in adult rat hippocampus (Lynch and Baudry, 1987; Staubli et al., 1988; Oliver et al., 1989; Vanderklish et al., 1995, 1996; Zadran et al., 2012). While it is tempting to assume that protein synthesis as well as proteolytic events could be involved in synaptic plasticity and in learning and memory, the relationships between these two processes are currently unknown.

BDNF and its signaling pathway play an important role in the cellular mechanisms underlying LTP and long-term memory (LTM) formation (Lynch et al., 2007; Rex et al., 2007; Bramham, 2008; Chen et al., 2010). BDNF-induced dendritic protein synthesis requires activation of the mammalian/mechanistic target of rapamycin (mTOR) pathway (Takei et al., 2004), which has also been implicated in LTM formation (Tang et al., 2002). The phosphatidylinositol-3' kinase (PI3K)-Akt and mitogenactivated protein kinase (MAPK) signaling pathways are upstream of mTOR and also participate in synaptic plasticity and memory formation (Cammalleri et al., 2003; Kelleher et al., 2004; Jaworski et al., 2005; Kumar et al., 2005; Ma et al., 2005). We showed previously that BDNF activates calpain-2 through extracellular regulated kinase (ERK)-mediated phosphorylation (Zadran et al., 2010). Thus, BDNF stimulates both protein synthesis and calpain activity in dendritic spines, and it is reasonable to assume the existence of a cross talk between these two processes. The present study was directed at testing the role of calpain in BDNF-mediated mTOR pathway activation. Phosphatase and tensin homolog deleted on chromosome 10 (PTEN) is a negative 
regulator of Akt (Jaworski et al., 2005), while the tuberous sclerosis 1 and 2 gene products, hamartin and tuberin, block mTOR signaling downstream of Akt and ERK (Inoki et al., 2002; Tee et al., 2003). Our results indicate that calpain-mediated PTEN, hamartin, and tuberin degradation is likely to account for BDNF-induced stimulation of dendritic protein synthesis, thus revealing a new and important function for calpain in the regulation of local protein synthesis.

\section{Materials and Methods}

Animals were treated in accordance with the principles and procedures of the National Institutes of Health Guide for the Care and Use of Laboratory Animals. All protocols were approved by the Institutional Animal Care and Use Committee of the University of Southern California and of Western University of Health Sciences.

Acute hippocampal slice preparation. Hippocampi were rapidly dissected from 8- to 10week-old male Sprague Dawley rats, transferred to oxygenated, ice-cold cutting medium [containing (in $\mathrm{mm}$ ) 220 sucrose, $20 \mathrm{NaCl}, 26$ $\mathrm{NaHCO}_{3}, 10$ glucose, $2.5 \mathrm{KCl}, 1.25 \mathrm{NaH}_{2} \mathrm{PO}_{4}$, and $2 \mathrm{MgSO}_{4}$ ], and cut into $400-\mu \mathrm{m}$-thick transverse slices using a Mcllwain tissue chopper. Hippocampal slices were maintained in a recovery chamber with artificial CSF (ACSF) medium containing (in mM) $124 \mathrm{NaCl}, 2.5 \mathrm{KCl}, 2.5 \mathrm{CaCl}_{2}$, $1.5 \mathrm{MgSO}_{4}, 1.25 \mathrm{NaH}_{2} \mathrm{PO}_{4}, 24 \mathrm{NaHCO}_{3}$, and 10 D-glucose, saturated with $95 \% \mathrm{O}_{2} / 5 \% \mathrm{CO}_{2}$, for $1 \mathrm{~h}$ at $37^{\circ} \mathrm{C}$. Hippocampal slices were then transferred into screw-cap microfuge tubes containing $2 \mathrm{ml}$ of freshly oxygenated ACSF medium with various drugs, including $10 \mu \mathrm{M}$ calpain inhibitor III (Calbiochem), $1 \mu \mathrm{M}$ rapamycin (Cell Signaling Technology), $5 \mu \mathrm{M}$ U0126 (Tocris Bioscience), $25 \mu$ M cycloheximide (Tocris Bioscience), $100 \mathrm{ng} / \mathrm{ml}$ BDNF (Millipore), and $50 \mu \mathrm{M}$ CX614 ( $2 \mathrm{H}, 3 \mathrm{H}, 6 a \mathrm{H}$-pyrrolidino $\left(2,1-3^{\prime}, 2^{\prime}\right)$ 1,3-oxazino $\left(6^{\prime}, 5^{\prime}-5,4\right)$ benzo(e) 1,4-dioxan-10-one; Cortex Pharmaceuticals), and were incubated at $37^{\circ} \mathrm{C}$ for the indicated periods of time.

Cortical synaptoneurosome preparation. Synaptoneurosomes were prepared from 8- to 10week-old male Sprague Dawley rats as described previously (Dominguez et al., 2007), with minor modifications. Briefly, cortices were rapidly dissected and placed into chilled modified Krebs solution (mKrebs) containing the following (in mM): $118.5 \mathrm{NaCl}, 4.7 \mathrm{KCl}, 1.18 \mathrm{KH}_{2} \mathrm{PO}_{4}, 24.9$ $\mathrm{NaHCO}_{3}, 1.18 \mathrm{MgSO}_{4}, 2.5 \mathrm{CaCl}_{2}, 10$ D-glucose, and 1 HEPES, pH 7.4, equilibrated with $95 \% \mathrm{O}_{2} /$ $5 \% \mathrm{CO}_{2}$. Cortices were homogenized in a $7 \mathrm{ml}$ Kontes tissue dounce homogenizer with 10 strokes. Homogenized tissue was filtered through a $100 \mu \mathrm{m}$ nylon mesh filter (BD Falcon), and the resulting suspension was filtered again through a $5-\mu \mathrm{m}$-pore size Acrodisc syringe filter with a Supor membrane (Pall Life Sciences). The filtrate was then centrifuged at $1000 \times g$ for $15 \mathrm{~min}$ at $4^{\circ} \mathrm{C}$, washed once, and centrifuged again. The pellet was resuspended in mKrebs, and various drugs were added directly to the prewarmed ( $5 \mathrm{~min}, 37^{\circ} \mathrm{C}$ ) synaptoneurosome suspension for the indicated periods of time.

Primary neuronal cultures. Cortices from embryonic day 18 rats (E18; Sprague-Dawley) and hippocampi from E18 mice (BALB/c) were digested with papain $(20 \mathrm{U} / \mathrm{ml})$ before mechanical dissociation, and neurons were

C
B

C $\quad \mathrm{Cl} \quad \mathrm{BDNF} \quad \mathrm{BD}+\mathrm{Cl} \quad \mathrm{CX} \quad \mathrm{CX}+\mathrm{Cl}$

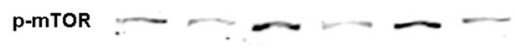

mTOR $\sim \sim \sim-$
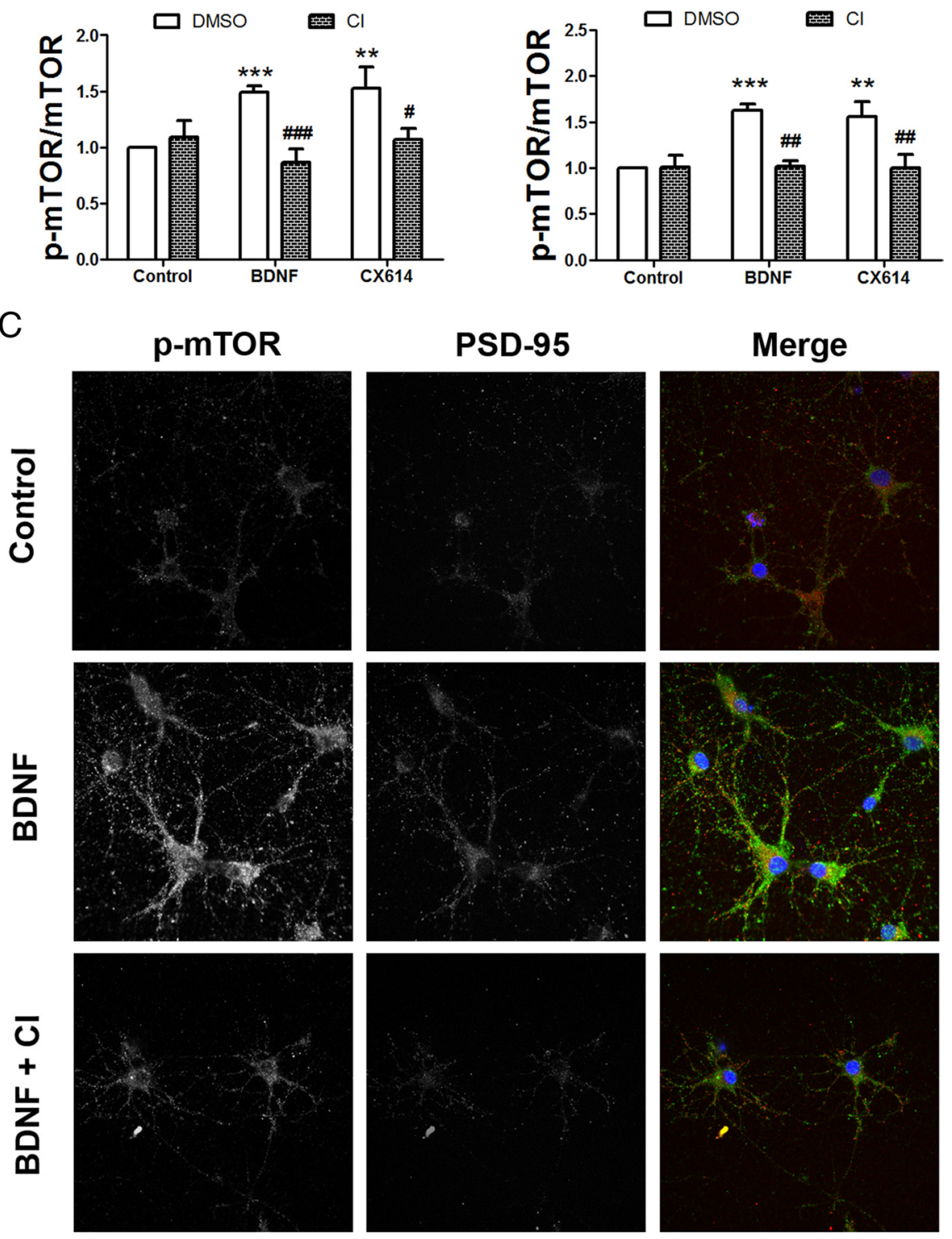

Figure 1. Effect of calpain inhibitor III on BDNF-mediated mTOR phosphorylation. $A, B$, Acute hippocampal slices $(\boldsymbol{A})$ and cortical synaptoneurosomes $(\boldsymbol{B})$ were pretreated with calpain inhibitor III $(\mathrm{Cl} ; 10 \mu \mathrm{M})$ for $30 \mathrm{~min}$ and then incubated with BDNF $(100 \mathrm{ng} / \mathrm{ml})$ or $\mathrm{CX} 614(\mathrm{CX} ; 50 \mu \mathrm{m})$ for $30 \mathrm{~min}$. Slices were homogenized and processed for Western blot. Data are presented as the ratio of phospho-mTOR over total $m$ TOR (fold of control) and are means \pm SEM from $4-12$ independent experiments. ${ }^{* *} p<0.01$, ${ }^{* * *} p<0.001$ (compared with control); $p<0.05$, ${ }^{\# \#} p<0.01$, ${ }^{\# \#} p<0.001$ (compared to BDNF or CX614 alone; two-way ANOVA). C, Primary cultured rat cortical neurons were pretreated with calpain inhibitor III $(10 \mu \mathrm{M})$ for $30 \mathrm{~min}$ and then incubated with BDNF ( $100 \mathrm{ng} / \mathrm{ml}$ ) for $30 \mathrm{~min}$. (ells were then fixed, immunostained for phospho-mTOR at Ser2448 (green) and for PSD-95 (red), and then labeled with DAPI (blue).

plated onto poly-D-lysine-coated dishes at low $\left(100-300\right.$ cells $\left./ \mathrm{mm}^{2}\right)$ density for imaging experiments and at high density for Western blot experiments (800-1000 cells $\left./ \mathrm{mm}^{2}\right)$, and maintained in Neurobasal medium supplemented with B27 (Gibco) and 10\% fetal bovine serum (FBS) in a humidified 5\% $\mathrm{CO}_{2} /$ 95\% air atmosphere at $37^{\circ} \mathrm{C}$ as described previously (Zadran et al., 2010).

Small interfering RNA transfection. Small interfering RNA (siRNA) transfection was performed as described previously (Qin et al. 2010), with few modifications. Forty microliters of siRNA $(20 \mu \mathrm{M})$ were combined with $680 \mu \mathrm{l}$ of $250 \mathrm{mM} \mathrm{CaCl}_{2}$ and $680 \mu \mathrm{l}$ of BES [N,N-bis(2- 
A
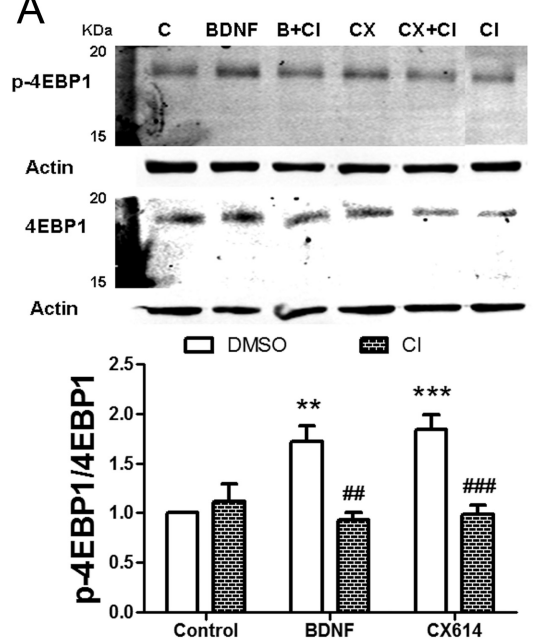

C C $\quad$ BDNF $\quad \mathrm{B}+\mathrm{Cl} \quad \mathrm{CX} \quad \mathrm{CX}+\mathrm{Cl} \quad \mathrm{Cl}$
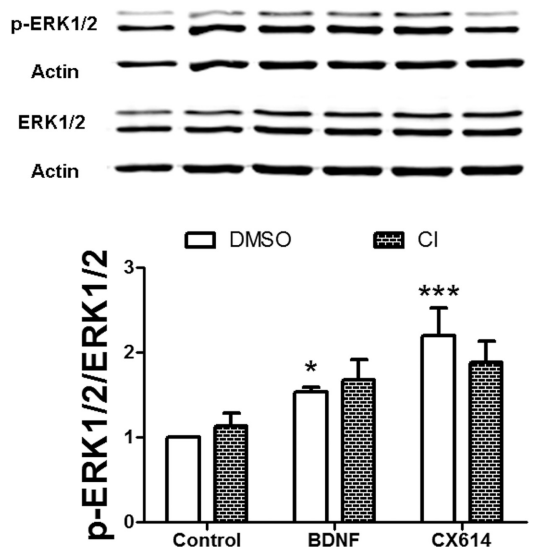

B
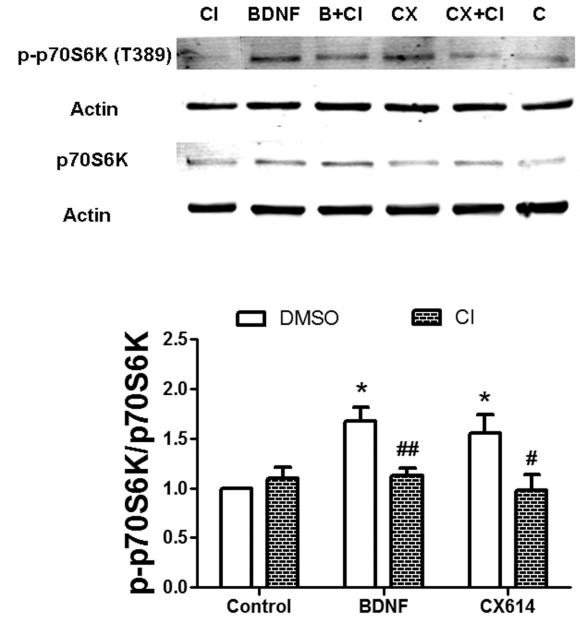

D
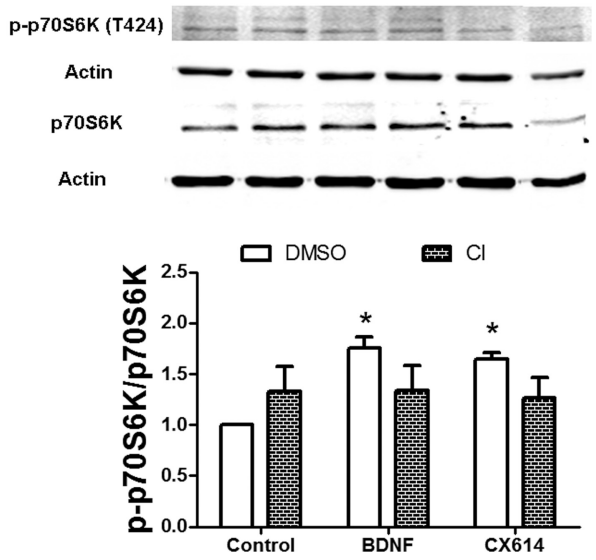

Figure 2. $\quad A-D$, Effect of calpain inhibitor III on BDNF-mediated phosphorylation of 4EBP1 $(A)$, p70S6K (B, D) and ERK1/2 (C). Acute hippocampal slices were pretreated with calpain inhibitor III (Cl; $10 \mu \mathrm{m}$ ) for 30 min and then incubated with BDNF (100 ng/ml) or CX614 (CX; $50 \mu \mathrm{m}$ ) for $30 \mathrm{~min}$. Slices were homogenized and processed for Western blot. Data are presented as the ratio of phosphorylated protein over total protein (fold of control) and are means \pm SEM from three to five independent experiments. ${ }^{*} p<0.05,{ }^{* *} p<0.01,{ }^{* * *} p<0.001$ (compared to control); $" p<0.05, " \# p<0.01,{ }^{\# \# \#} p<0.001$ (compared to BDNF or CX614 alone; two-way ANOVA).

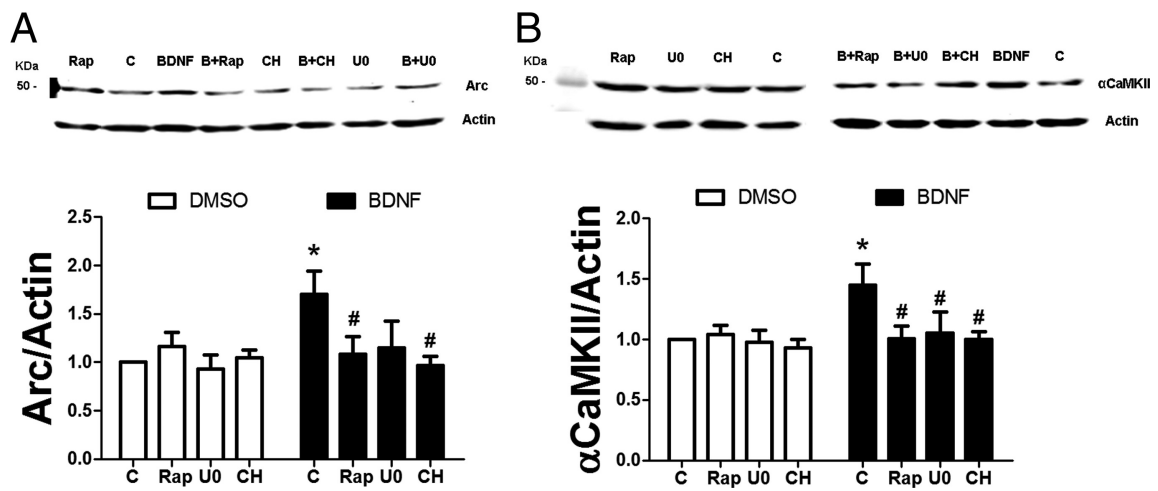

Figure 3. Effects of rapamycin, cycloheximide, and an MAP kinase inhibitor (U0126) on BDNF-mediated increase in Arc and CaMKIl in acute hippocampal slices. $A, B$, Acute hippocampal slices were pretreated with DMSO $(0.01 \%)$, rapamycin $(1 \mu \mathrm{M})$, cycloheximide $(25 \mu \mathrm{m})$, or U0126 $(5 \mu \mathrm{m})$ for $30 \mathrm{~min}$ and then incubated with BDNF $(100 \mathrm{ng} / \mathrm{ml})$ for $30 \mathrm{~min}$. Slices were homogenized and processed for Western blot for $\operatorname{Arc}(\boldsymbol{A})$ and $\operatorname{CaMKII}(\boldsymbol{B})$. Data are normalized to the levels of actin and are expressed as ratio over control values; they are means \pm SEM from three to five independent experiments. ${ }^{*} p<0.05$ (compared to vehicle); ${ }^{*} p<0.05$ (compared to BDNF alone; two-way ANOVA).

hydroxyethyl)-2-aminoethanesulfonic acid], $\mathrm{pH} 7.1$, and incubated at room temperature for $30 \mathrm{~min}$. Cultured cortical neurons grown for $7 \mathrm{~d}$ in vitro (DIV) in $35 \mathrm{~mm}$ dishes (BD Falcon) were incubated with prewarmed MEM/EBSS (Hyclone), and the siRNA mixture was added di- rectly to the cultures and incubated at $37^{\circ} \mathrm{C}$ for $3 \mathrm{~h}$. Cultured neurons were then changed to fresh culture medium and maintained for $24 \mathrm{~h}$ in a humidified $5 \% \mathrm{CO}_{2} / 95 \%$ air atmosphere at $37^{\circ} \mathrm{C}$ before treatments were performed. The following siRNA sequences were used: negative control(scrambledsiRNA),AATTCTCCGAAC GTCTCACGT; calpain-1, TACCTCTGTTCA ATTGCTCTA; calpain-2, GCGGTCAGATAC CTTCATCAA (Qiagen).

Preparation of $P 2$ membranes from brain homogenates. Brains were removed from two to three Sprague Dawley rats and placed in icecold homogenization buffer containing the following: $320 \mathrm{~mm}$ sucrose, $10 \mathrm{~mm}$ HEPES, $\mathrm{pH}$ 7.4, 2 mм EDTA, 2 mм EGTA, 0.1 mм PMSF, and protease inhibitor cocktail (Thermo Scientific). Brain tissue was homogenized with 10 strokes using a $55 \mathrm{ml}$ Wheaton glass-Teflon homogenizer. The homogenate was centrifuged at $1000 \times g$ for $10 \mathrm{~min}$, and the resultant supernatant was collected and centrifuged at $14,000 \times g$ for $20 \mathrm{~min}$. The resultant pellet (P2 membrane fraction) was centrifuged again at $14,000 \times g$ for $20 \mathrm{~min}$ to eliminate protease inhibitors. $\mathrm{P} 2$ pellets were then resuspended in Tris-acetate buffer (100 mm Tris-acetate, $\mathrm{pH}$ 7.4, $50 \mu \mathrm{M}$ EGTA), and the protein concentration was determined by the BCA assay (Thermo Scientific). Equal amounts of proteins $(4 \mu \mathrm{g} / \mu \mathrm{l})$ were incubated with calpain-1 (Calbiochem) or calpain-2 (Origene) (both at $2.4 \mathrm{U} / \mathrm{ml}$ ) in the absence and presence of $2 \mathrm{~mm}$ calcium for $30 \mathrm{~min}$ at $37^{\circ} \mathrm{C}$. In some experiments, different concentrations $(1-5 \mathrm{U} / \mathrm{ml})$ of calpain-1 and calpain-2 were used. Calpain reaction was stopped by adding Laemmli's loading buffer (final concentrations, 62.5 mM Tris-HCl, pH 6.8, 2\% sodium dodecyl sulfate, $10 \%$ glycerol, $0.005 \%$ bromophenol, $5 \%$ $\beta$-mercaptoethanol) followed by boiling at $100^{\circ} \mathrm{C}$ for $5 \mathrm{~min}$, and samples were then subjected to Western blot.

Detection of purified PTEN by Coomassie blue staining. Equal amounts of purified human PTEN (4 $\mu \mathrm{g}$; Cayman Chemicals) were incubated in Tris-acetate buffer with $2 \mathrm{~mm}$ calcium and calpain-1 (10 $\mu \mathrm{g}$; Calbiochem) or calpain-2 (10 $\mu \mathrm{g}$; a generous gift from Dr. Peter Davies, Queen's University, Ontario, CA) for $1 \mathrm{~h}$ at $37^{\circ} \mathrm{C}$. After incubation, $1 \mu \mathrm{g}$ of protein from each sample was subjected to $15 \%$ SDS-PAGE, and the gel was incubated with Coomassie blue $(1 \mathrm{mg} / \mathrm{ml})$ prepared in acidic solution (40\% methanol, 10\% acetic acid) for $20 \mathrm{~min}$ at room temperature and washed several times with acidic solution before being scanned.

Western blot. Protein lysates were prepared at a final concentration of $4-8 \mu \mathrm{g} / \mu \mathrm{l}$ by homogenization of rat hippocampal slices, cortical synaptoneurosomes, or cultured neurons in cold lysis buffer [containing (in mM) 50 Tris$\mathrm{HCl}, \mathrm{pH}$ 7.4, $150 \mathrm{NaCl}, 5$ EDTA, 1 EGTA, 1 PMSF, $10 \mathrm{NaF}$, and $1 \mathrm{Na}_{3} \mathrm{VO}_{4}$ ] containing protease inhibitor cocktail (Thermo Scientific). After sample processing (as described above), $25-40 \mu \mathrm{g}$ of denatured proteins were subjected to $6-15 \%$ SDS-PAGE and transferred onto polyvinylidene difluoride membranes. Membranes were blocked with 5\% nonfat milk dissolved in Tris-buffered saline 
(TBS) for $1 \mathrm{~h}$ at room temperature and probed overnight with different primary antibodies at $4^{\circ} \mathrm{C}$. Membranes were then washed three times with TBST for $10 \mathrm{~min}$ followed by incubation with Odyssey infrared-conjugated secondary antibodies diluted 1:10,000 in Odyssey blocking buffer for $1 \mathrm{~h}$ at room temperature. After three 10 min washes with TBST, membranes were scanned using an Odyssey infrared imager (LI-COR Biosciences).

Antibodies. All primary antibody solutions were prepared in TBS containing $0.1 \%$ of Tween 20 and $3 \%$ bovine serum albumin at a 1:1000 dilution unless stated otherwise. The following primary antibodies were used: anti-phosphomTOR (Ser2448) and anti-mTOR (both from Cell Signaling Technology), anti-phospho4EBP1 (Thr37/46; Millipore), anti-4EBP1 (Cell Signaling Technology), anti-phospho-p70S6K (Thr389 from Millipore and Thr421/Ser424 from Cell Signaling Technology), anti-p70S6K (Cell Signaling Technology), anti-phosphoERK1/2 (Thr202/Tyr204) and anti-ERK1/2 (both at 1:2000; Cell Signaling Technology), antiArc (1:5,000; Millipore), anti- $\alpha$ CaMKII (Cell Signaling Technology), anti-phospho-Akt (Ser473) and anti-Akt (both from Cell Signaling Technology), anti-hamartin (Cell Signaling Technology), anti-phospho-tuberin (Tyr1462) and anti-tuberin (both from Cell Signaling Technology), anti-phospho-PTEN (Ser380/Thr382/ Thr383; Cell Signaling Technology), antiphospho-TrkB (Tyr 490) and anti-TrkB (both from Cell Signaling Technology), anti-actin (1:10,000; Millipore), and anti-phospho(Tyr) p85 PI3K binding motif (Cell Signaling Technology). To detect PTEN, we routinely tested different primary antibodies within the same membrane: a rabbit polyclonal and a mouse monoclonal anti-PTEN (both from Cell Signaling Technology).

Immunocytochemistry. Cultured hippocampal neurons were grown for 14 DIV in coverslips within six-well plates, and the media was switch to fresh neurobasal without serum at least $3 \mathrm{~h}$ before the treatments were performed. After the treatments, cultures were rinsed with $\mathrm{PBS}$ [containing (in $\mathrm{mm}$ ) $137 \mathrm{NaCl}, 2.7 \mathrm{KCl}, 10 \mathrm{Na}_{2} \mathrm{HPO}_{4}$, and 2 $\mathrm{KH}_{2} \mathrm{PO}_{4}$ ] and fixed in methanol at $-20^{\circ} \mathrm{C}$ for $10 \mathrm{~min}$. Cells were permeabilized with $0.1 \%$ Triton X-100 in PBS for 15 min and blocked at room temperature for $30 \mathrm{~min}$ in PBS containing $10 \%$ FBS and $0.05 \%$ Triton $\mathrm{X}-100$. Subsequently, cells were incubated overnight at $4^{\circ} \mathrm{C}$ with primary rabbit antiphospho-mTOR antibody (1:250) and mouse anti-PSD-95 (1:500; Stressgen) in PBS containing 3\% BSA, $0.05 \%$ Triton X-100, and $0.05 \%$ sodium azide (PBSBSA). After four 15 min washes with PBS-BSA, cells were incubated with secondary anti-rabbit Alexa Fluor 488- and anti-mouse Alexa Fluor 566-conjugated antibodies (both at 1:1000; Invitrogen) diluted in PBS-BSA for another $1 \mathrm{~h}$ at room temperature. After washing out with PBS-BSA (four times for $15 \mathrm{~min}$ each), cells were sealed in slides with mounting medium containing DAPI (Vector Laboratories). The immunostained cells were examined under a confocal fluorescence microscope (Nikon).

Dendritic protein translation and image quantification. Local protein synthesis in dendrites was measured as described previously (Aakalu et
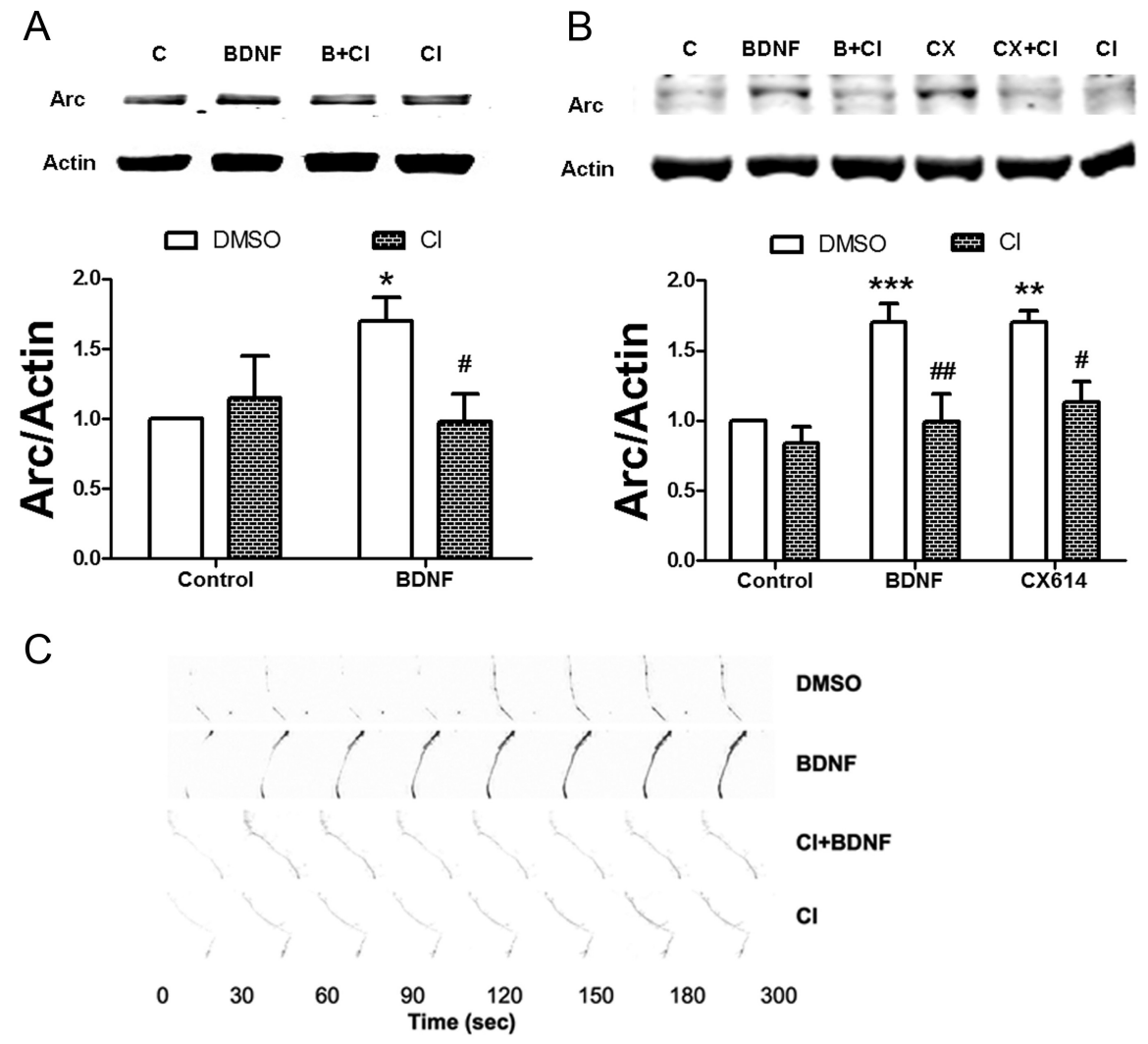

Figure 4. Effect of calpain inhibitor III on BDNF-induced increase in dendritic protein synthesis. $\boldsymbol{A}, \boldsymbol{B}$, Acute hippocampal slices $(\boldsymbol{A})$ and cortical synaptoneurosomes $(\boldsymbol{B})$ were pretreated with calpain inhibitor III $(\mathrm{Cl} ; 10 \mu \mathrm{M})$ for 30 min and then incubated with BDNF $(100 \mathrm{ng} / \mathrm{ml})$ or CX614 (CX; $50 \mu \mathrm{m})$ for $30 \mathrm{~min}$. Slices were homogenized and processed for Western blot. Data are presented as the ratio of Arc over actin (fold of control) and are means \pm SEM from five to eight independent experiments. ${ }^{*} p<0.05,{ }^{* *} p<0.01,{ }^{* * *} p<0.001$ (compared to control); ${ }^{*} p<0.05,{ }^{\# \#} p<0.01$ (compared to BDNF or CX614 alone; two-way ANOVA). C, Cultured mouse hippocampal neurons that were transfected with the GFP reporter plasmid were preincubated with calpain inhibitor III (10 $\mu \mathrm{m})$ for $60 \mathrm{~min}$, and vehicle or BDNF (100 ng/ml) was applied. Selected dendritic branches were "photobleached" until fluorescence was almost invisible. Time-lapse images were then taken at 30 s intervals. Fluorescence intensity was quantified and values expressed as percent of values measured at time $0\left(t_{0}\right)$. Results are means \pm SEM of three experiments (results from each experiments were averaged values determined from 3-5 dendrites, 1-2 dendrites per neuron) from three independent culture preparations. ${ }^{* * *} p<0.001$ (compared to control; one-way ANOVA followed by Tukey's post-test analysis).

al., 2001; Jourdi et al., 2009). A translation reporter plasmid containing myristoylated GFP (myrGFP) cDNA flanked by $3^{\prime}$ and $5^{\prime}$ untranslated regions (UTRs) of $\alpha$ CamKII (a generous gift from Dr. E. M. Schuman, Caltech, Pasadena, CA) was used and transfected into hippocampal neurons prepared from E18 BALB/c mouse embryos. Myristoylation of the translation reporter prevents the diffusion of locally translated GFP protein. Twenty-four hours after transfection, neurons were washed with imaging buffer, and DMSO or calpain inhibitor III $(10 \mu \mathrm{M})$ was added. After $60 \mathrm{~min}, \mathrm{BDNF}(100 \mathrm{ng} / \mathrm{ml})$ or vehicle was added, and GFP-labeled dendritic branches were successively selected. Dendritic branches were photobleached by excitation at $488 \mathrm{~nm}$ to eliminate the GFP signal and then processed for time-lapse imaging every $30 \mathrm{~s}$. The overall treatment 
A C $\quad \mathrm{Cl}$ BDNF $\mathrm{B}+\mathrm{Cl} \quad \mathrm{CX} \quad \mathrm{CX}+\mathrm{Cl}$
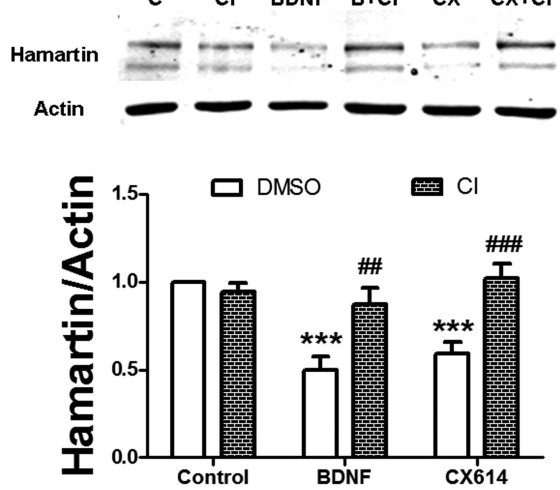

C

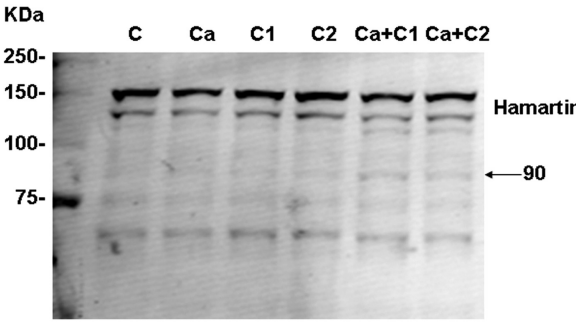

D

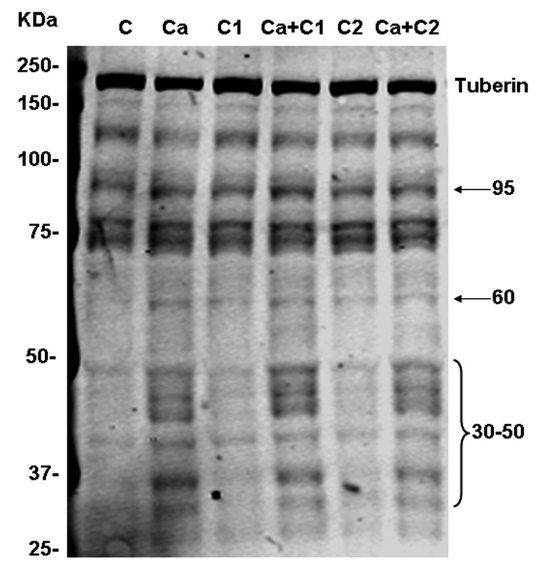

$E$

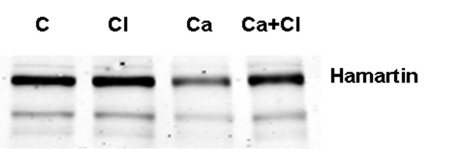

B
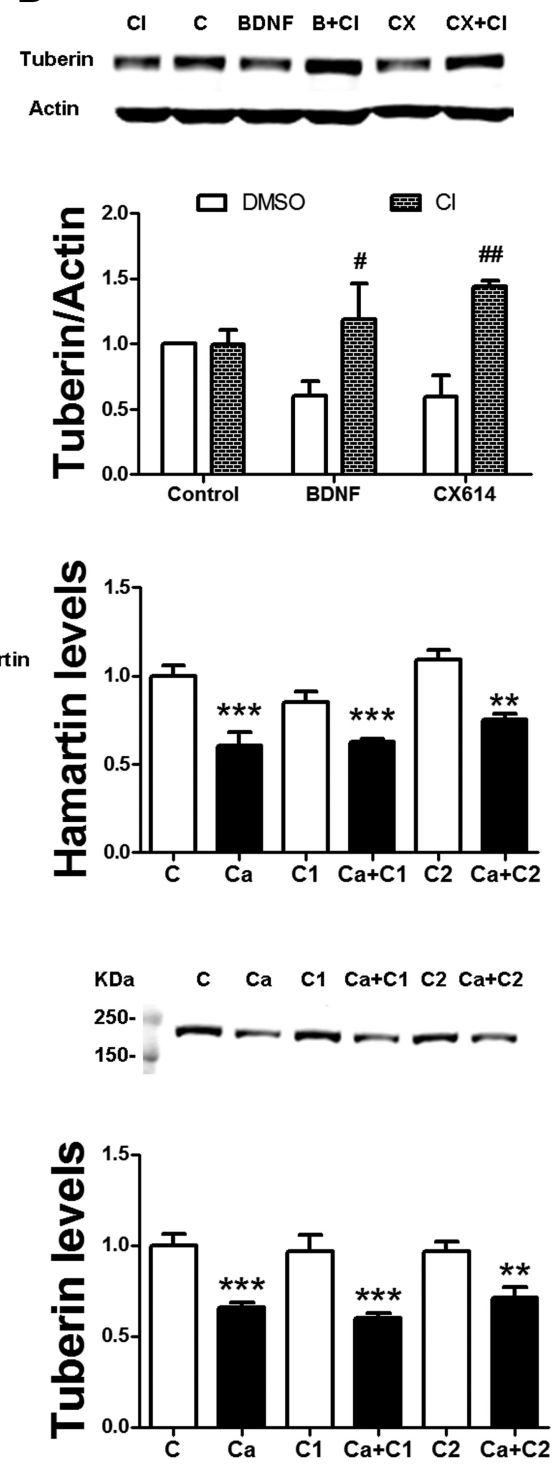

C $\mathrm{Cl} \mathrm{Ca} \mathrm{Ca}+\mathrm{Cl}$

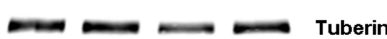

Figure 5. Effects of calpain activation/inhibition on hamartin and tuberin levels. $A, B$, Acute hippocampal slices were pretreated with calpain inhibitor III (Cl; $10 \mu \mathrm{m})$ for 30 min and then incubated with BDNF (100 ng/ml) or CX614 (CX;50 $\mu \mathrm{m})$ for $30 \mathrm{~min}$. Slices were homogenized and processed for Western blot. Data are presented as the ratio of hamartin/tuberin over actin (fold of control) and are means \pm SEM from 4-10 independent experiments. ${ }^{* * *} p<0.001$ (compared to control); ${ }^{\#} p<0.05,{ }^{\# \#} p<0.01$, $\# \# \#<0.001$ (compared to BDNF or CX614 alone; two-way ANOVA). C, $D$, Equal amount of proteins from brain homogenates were treated with vehicle, $2 \mathrm{~mm}$ calcium chloride, calpain I or II and the combination of calcium and calpain-1 or calpain-2 (both at 2.4 unit) for $30 \mathrm{~min}$. After incubation, samples were processed for Western blot. Data are presented as total levels of hamartin and tuberin (fold of control) and are means \pm SEM from six to eight independent experiments. ${ }^{* *} p<0.01$; ${ }^{* * *} p<0.001$ (compared to control; one-way ANOVA followed by Dunnett's multiple comparison test). Note that a saturated (overexposed) blot is presented on the left of $\boldsymbol{D}$ to show tuberin breakdown products, and the same nonsaturated blot is presented on the right of the panel to show the differences in full-length tuberin among the treatments. $\boldsymbol{E}$, To verify that the calcium effects on hamartin and tuberin were mediated by activation of endogenous calpain, membrane fractions were preincubated with calpain inhibitor III and then incubated in the absence or presence of calcium ( $2 \mathrm{~mm})$ for $30 \mathrm{~min}$. After incubation, samples were processed for Western blot.

with BDNF ranged between 2 and 15 min; GFP fluorescence recovery therefore reflects both the rate of protein synthesis and maturation.

Statistical analysis. Statistical comparisons were made by using oneway ANOVAs followed by Dunnett's multiple comparison test or by
Tukey's post-test and two-way ANOVA followed by Bonferroni's post-test analysis. Results were generally calculated as means \pm SEM from the indicated number of independent experiments and expressed as fold of the indicated control. $p$ values $>0.05$ were regarded as not significant.

\section{Results}

Calpain activation is required for BDNF-induced $m$ TOR activation in acute hippocampal slices, cortical synaptoneurosomes, and cultured neurons

Previous studies showed that BDNF increases mTOR-mediated dendritic protein synthesis in acute rat hippocampal slices and neuronal cultures (Takei et al., 2004; Jourdi et al., 2009). To examine whether calpain plays a role in BDNFinduced mTOR phosphorylation, we pretreated acute hippocampal slices with calpain inhibitor III $(10 \mu \mathrm{M})$, and $30 \mathrm{~min}$ later BDNF (100 $\mathrm{ng} / \mathrm{ml})$ was applied for another $30 \mathrm{~min}$. BDNF treatment significantly increased mTOR phosphorylation in acute hippocampal slices, and this effect was completely reversed by pretreatment with calpain inhibitor III (Fig. 1A). Calpain inhibitor alone did not significantly change the phosphorylation state of mTOR compared to vehicle-treated control. To confirm these effects, we treated acute hippocampal slices with the ampakine CX614, which has been shown to enhance endogenous BDNF release and activate the mTOR pathway (Jourdi et al., 2009). Bath application of CX614 (50 $\mu \mathrm{M}, 30 \mathrm{~min}$ ) increased the phosphorylation of mTOR to a similar extent as BDNF treatment. This effect was also prevented by pretreatment with calpain inhibitor III (Fig. 1A). We further tested the effects of BDNF and CX614 on mTOR activation in a synaptoneurosomal preparation from rat cerebral cortices. Calpain inhibition abolished both BDNF- and CX614-induced increase in mTOR phosphorylation, without affecting the basal levels of activated mTOR (Fig. 1B). In addition, we evaluated mTOR activation in primary cultures of cortical neurons by performing double-immunocytochemistry for phospho-mTOR and for the postsynaptic marker PSD-95. Consistent with the above data, treatment with BDNF strongly enhanced phospho-mTOR immunostaining within dendritic processes, and this effect was reversed by calpain inhibitor III (Fig. 1C). BDNF treatment also increased PSD-95 immunofluorescence, which was partially colocalized with phospho-mTOR, and this effect was also blocked by calpain inhibition. 
Calpain inhibition suppresses mTORdependent stimulation of the protein translation machinery

Stimulation of dendritic protein synthesis by BDNF involves the activation of different translation factors, such as the eukaryotic initiation factor $4 \mathrm{E}$ (eIF4E). Under basal conditions, eIF4E activity is negatively regulated by the eIF4E binding protein 1 (4EBP1). Phosphorylation at Thr37 by mTOR signaling causes 4EBP1 to dissociate from eIF4E and allows the initiation of cap-dependent protein translation. Thus, we tested the effect of calpain inhibition on BDNF-mediated increase in 4EBP1 phosphorylation in acute hippocampal slices. Treatment with either BDNF or CX614 increased the phosphorylation of 4EBP1, and these effects were totally suppressed in the presence of calpain inhibitor III (Fig. 2A). As the antibody we used to label p-4EBP1 also recognizes p-4EBP1/2/3, we cannot exclude the role of other $4 \mathrm{EBPs}$, in particular $4 \mathrm{EBP} 2$, which is enriched in the brain (Bidinosti et al., 2010), in the activation of mTOR and the stimulation of local protein synthesis.

Another important step for BDNF-stimulated dendritic protein synthesis is the phosphorylation of p70S6K, which ultimately activates the ribosomal protein S6 leading to 5' -oligopyrimidine tract-containing mRNA translation (Takei et al., 2004). Two different phosphorylation sites within p70S6K (Thr389 and Thr421/ Ser424) regulate its activity, both being dependent on mTOR signaling (Zhou et al., 2010). We thus tested the effect of calpain inhibitor III on BDNF-mediated activation of p70S6K by using antibodies that specifically recognize these phosphorylation sites. Treatment of acute hippocampal slices either with BDNF or CX614 enhanced p70S6K phosphorylation both at Thr389 and Thr421/Ser424. Stimulation of Thr389 phosphorylation by BDNF and CX614 was completely reversed by calpain inhibition (Fig. 2B). In contrast, although calpain inhibitor III decreased BDNF-mediated increase in Thr421/Ser424 phosphorylation, this effect did not reach statistical significance (Fig. 2D). Besides being regulated by $\mathrm{mTOR}$ activity, phosphorylation of p70S6K at Thr421/Ser424 can also be mediated by the MAPK pathway (Zhou et al., 2010). Furthermore, calpain activity is directly regulated by ERK1/2 phosphorylation (Zadran et al., 2010). Hence, the lack effect of calpain inhibitor III against BDNF-induced Thr421/Ser424 phosphorylation might be due to the fact that MAPK activation is upstream of calpain. To directly test this hypothesis, we examined the effect of calpain inhibition on BDNF-induced ERK1/2 activation in acute hippocampal slices. Pretreatment with calpain inhibitor III did not prevent the increase in ERK1/2 phosphorylation caused by either BDNF or CX614 (Fig. 2C).

Calpain activation is required for BDNF-induced dendritic protein synthesis in acute hippocampal slices, cortical synaptoneurosomes, and cultured neurons

BDNF stimulates dendritic Arc mRNA translation through activation of mTOR-dependent signaling in primary cortical neurons and in synaptoneurosomes (Takei et al., 2004; Jourdi et al., 2009). Conversely, in vivo Arc synthesis in the dentate gyrus is rapamycin insensitive but sensitive to MAPK inhibi- tors (Panja et al., 2009). Thus, we sought to determine whether the effects of BDNF on Arc expression were mediated by mTOR or by MAPK activities in adult rat hippocampal slices. Bath application of BDNF induced a significant increase in Arc levels compared to vehicle-treated control, and this effect was reversed by rapamycin $(1 \mu \mathrm{M})$ as well as by the protein synthesis inhibitor cycloheximide $(25 \mu \mathrm{M})$. The MAPK inhibitor U0126 $(5 \mu \mathrm{M})$ also reduced the increase in Arc translation caused by BDNF, although the effect did not reach statistical significance (Fig. 3). In contrast, all three inhibitors completely suppressed the increase in $\alpha$ CaMKII levels induced by BDNF (Fig. 3), indicating that activation of both mTOR and MAPK is necessary to stimulate rapid protein synthesis in hippocampal slices.

Since calpain activation is required for BDNF-induced mTOR signaling, we determined whether calpain inhibition would abrogate BDNF-induced Arc protein synthesis. Acute hippocampal slices were pretreated with calpain inhibitor III, and subsequently treated with or without BDNF, and Arc levels were determined by Western blotting. BDNF-induced stimulation of Arc expression was completely blocked by calpain inhibitor III (Fig. 4A), whereas treatment with calpain inhibitor III alone did not modify Arc levels. Likewise, we determined whether calpain activity was also required for BDNF-mediated stimulation of Arc synthesis in cortical synaptoneurosomes. As shown in Figure $4 B$, calpain inhibitor III blocked both BDNF- and CX614-induced Arc expression in this preparation.

We further examined the role of calpain in BDNF-induced dendritic protein synthesis by using a GFP protein translation reporter under the control of the UTR of $\alpha$ CaMKII (Aakalu et al., 2001). In cultured hippocampal neurons, transfection with the GFP- $\alpha$ CaMKII plasmid provides an efficient tool to analyze the effects of BDNF on dendritic protein synthesis. As shown previously (Jourdi et al., 2009), BDNF rapidly stimulated GFP synthesis/maturation in dendrites of cultured neurons. Pretreatment with calpain inhibitor III completely inhibited BDNF-induced increase in GFP protein synthesis/maturation, whereas it did not modify the rate of protein synthesis/maturation under control conditions (Fig. 4C). 
A
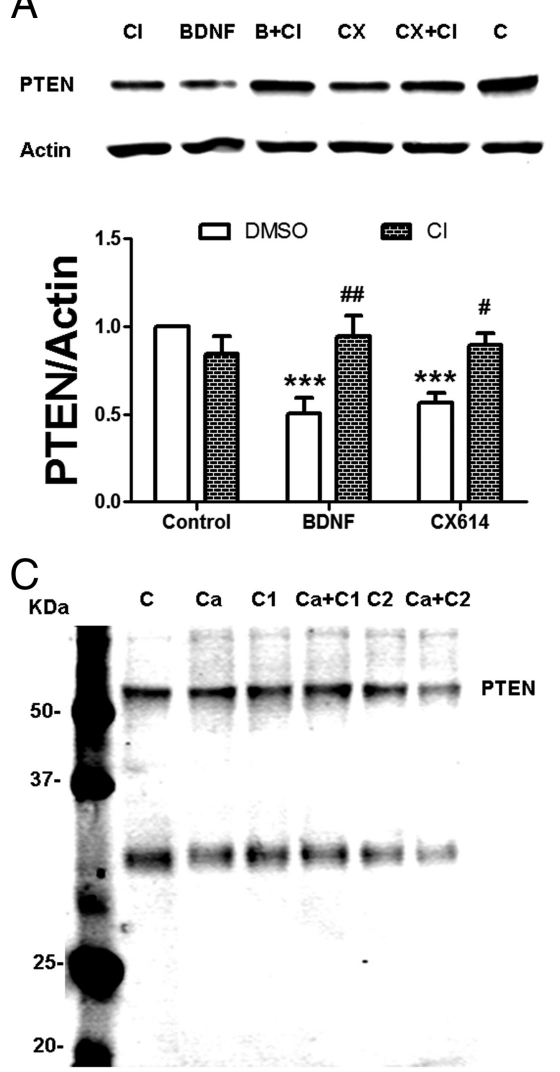

D

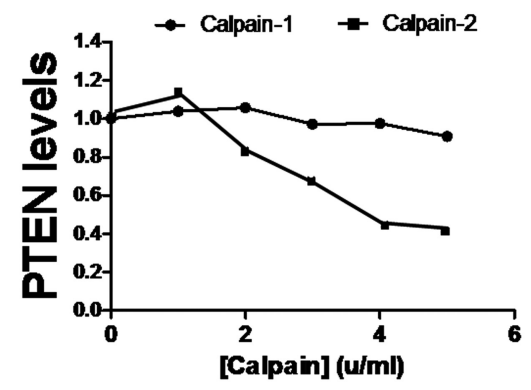

B
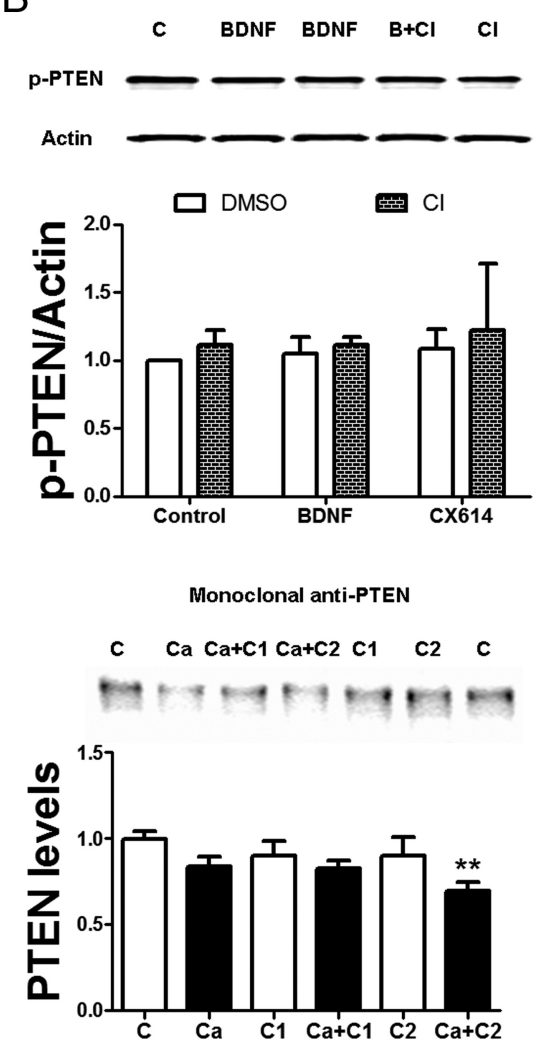

$E_{\text {KDa }}$

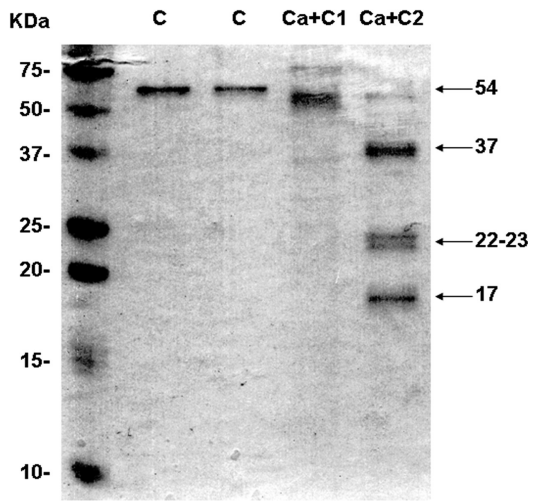

Figure 7. Effects of calpain activation/inhibition on PTEN levels. $A, B$, Acute hippocampal slices were pre-treated with calpain inhibitor III (Cl; $10 \mu \mathrm{M})$ for 30 min and then incubated with BDNF (100 ng/ml) or CX614 (CX; $50 \mu \mathrm{m})$ for 30 min. Slices were homogenized and processed for Western blot. Data are presented as the ratio of PTEN or phospho-PTEN over actin (fold of control) and are means \pm SEM from four to nine independent experiments. ${ }^{* * *} p<0.001$ (compared to control); ${ }^{\#} p<0.05,{ }^{\# \#} p<0.01$ (compared to BDNF or CX614 alone; two-way ANOVA). C, D, Equal amount of proteins from brain homogenates were treated with vehicle (C), 2 mm calcium (Ca), calpain-1 (C1), or calpain-2 (C2), and the combination of calcium and calpain-1 or calpain-2 (both at 2.4 units or at the indicated concentrations) for $30 \mathrm{~min}$ at $37^{\circ} \mathrm{C}$. After incubation, samples were processed for Western blot. Data are presented as total levels of PTEN (fold of control) and are means \pm SEM from 5-12 independent experiments. ${ }^{* *} p<0.01$ (compared to control; one way- ANOVA followed by Dunnett's multiple comparison test). $\boldsymbol{E}$, Equal amounts of purified human PTEN (4 $\mu \mathrm{g}$ ) were incubated with vehicle (C) and with $2 \mathrm{~mm}$ calcium and calpain-1 (10 $\mu \mathrm{g})$ or calpain-2 (10 $\mu \mathrm{g})$ for $1 \mathrm{~h}$ at $37^{\circ} \mathrm{C}$. After incubation, $1 \mu \mathrm{g}$ of proteins from each sample was subjected to SDS-PAGE and the gel stained with Coomassie blue $(1 \mathrm{mg} / \mathrm{ml})$.

BDNF-mediated calpain activation leads to hamartin and tuberin degradation

Our results indicated that calpain activation is a necessary step for the initiation of dendritic protein synthesis. To identify the molecular targets of calpain involved in this process, we determined the protein levels of several potential target proteins upstream of mTOR. mTOR activity is negatively regulated by the protein complex formed by hamartin and tuberin (Inoki et al., 2002). We determined the levels of these proteins after treatment with BDNF and CX614 in acute hippocampal slices. Stimulation with either BDNF or CX614 caused a reduction in both hamartin and tuberin levels, although the effects only reached statistical significance for the former. Furthermore, pretreatment with calpain inhibitor III reversed BDNF-mediated hamartin and tuberin downregulation (Fig. 5A,B). Similar effects were observed in cortical synaptoneurosomes (data not shown).

To confirm that hamartin and tuberin are actual targets of calpain, we incubated P2 membrane fractions prepared from adult rat forebrain in the presence of 2 $\mathrm{mm}$ calcium and purified calpain-1 or calpain-2 (both at $2.4 \mathrm{U} / \mathrm{ml}$ ) for $30 \mathrm{~min}$ at $37^{\circ} \mathrm{C}$. Treatment either with calpain- 1 or calpain-2 in the presence of calcium reduced the levels of both hamartin and tuberin in $\mathrm{P} 2$ membranes (Fig. 5C,D). Furthermore, treatment with calcium alone reduced hamartin and tuberin to a similar extent as in the presence of calpain-1 and calpain-2, suggesting that endogenous calpain activation is sufficient to cleave these proteins. Consistent with this notion, calpain inhibitor III prevented both hamartin and tuberin degradation caused by calcium treatment (Fig. $5 E$ ). A single breakdown product [of an approximate molecular weight (MW) of $90 \mathrm{KDa}]$ was detected for hamartin after calcium and calpain treatment (Fig. 5C). Analysis of hamartin protein sequence by using the calpain cleavage site predictor tool (www.calpain.org) indicated that Leu369 was the most likely truncation site (score of 0.18 ) that would generate a $\mathrm{C}$ terminus fragment of $88.015 \mathrm{KDa}$ that matches the apparent MW of the observed band.

An increase in several tuberin breakdown products was observed in brain homogenates treated with calcium and with calcium plus calpain-1 or calpain-2, with a band of $\sim 95 \mathrm{KDa}$ and several bands of 30 to $60 \mathrm{KDa}$, which suggested the existence of multiple cleavage sites within the protein. Among all the potential truncation sites suggested by the calpain cleavage site predictor tool, Leu940 and Gly1259 (with scores of 0.19 and 0.14 , respectively) are good candidates, since truncation at these sites would produce C-terminal fragments of 94.64 and $60.84 \mathrm{KDa}$, respectively, which correspond to the two higher bands observed. The remaining bands with MW 30-50 KDa might result from two sequential truncations at different sites, including Met830 (0.22), Gly1157 (0.15), Arg1731 (0.18), and again Gly1259 (0.14).

Tuberin activity is regulated by phosphorylation at Tyr1456, which causes the protein to dissociate from hamartin and allows 
mTOR activation (Inoki et al., 2002). Hence, we wondered whether phosphorylation of tuberin at this site could be altered by BDNF and CX614 treatment. Although total levels of tuberin were reduced by BDNF and CX614 treatment, we found a slight increase in tuberin phosphorylation in BDNF- and CX614stimulated hippocampal slices. The effects were statistically different from control conditions when expressed as a ratio of phospho-tuberin/tuberin (Fig. 6A). Interestingly, BDNF- and CX614-induced tuberin phosphorylation were also blocked by calpain inhibitor III, suggesting the existence of another calpain substrate upstream of the hamartin/tuberin protein complex. To investigate this possibility, we determined the effect of calpain inhibitor III on BDNF- and CX614-induced Akt phosphorylation, as this kinase is responsible for the phosphorylation of tuberin at Tyr1456 (Inoki et al., 2002). BDNF and CX614 treatment of hippocampal slices resulted in increased Akt phosphorylation, and these effects were completely blocked by calpain inhibition (Fig. 6B).

\section{BDNF and CX614 treatments cause} calpain-dependent PTEN degradation

PTEN negatively regulates protein synthesis through the inhibition of Akt. Therefore, we determined whether BDNF-induced increase in mTOR signaling in hippocampal slices could be also due to alterations in PTEN levels. BDNF and CX614 treatment of hippocampal slices induced a small but significant decrease in PTEN levels compared to control slices; this effect was blocked by pretreatment with calpain inhibitor III (Fig. 7A). PTEN function and stability are regulated by a number of posttranslational modifications, including protein phosphorylation (Torres and $\mathrm{Pu}$ lido, 2001; Barata, 2011). Therefore, we also assessed the levels of phospho-PTEN after treatment with BDNF in the absence or presence of calpain inhibitor III by using an antibody that recognizes three phosphorylation sites in the C-terminal domain of PTEN (Ser380/Thr382/Thr383). No differences in phospho-PTEN levels were found across the four treatment groups (Fig. $7 B$ ).

As the previous results suggested that PTEN could be degraded as a result of calpain activation, we directly examined whether or not PTEN was a substrate of calpain in brain. Thus, P2 membranes from brain homogenates were treated with purified calpain-1 or calpain-2 as described above, and PTEN levels were analyzed by Western blot. Interestingly, calcium alone or calcium plus calpain-1 treatment did not significantly alter PTEN levels, and only treatment with calcium and calpain-2 resulted in a statistically significant decrease in PTEN levels, compared with control conditions (Fig. 7C). We also used a monoclonal antibody raised against PTEN and obtained similar results as with the polyclonal antibody. Nevertheless, we did not detect any increase in lower MW fragments still recognized by either of the PTEN antibodies following calcium plus calpain-2 treatment, suggesting that the calpain truncation site might be closed to the epitope recognized by the antibodies in the $\mathrm{C}$ terminus (Fig. $7 C$ ). To confirm the differential effects of calpain-1 and calpain-2 on
PTEN truncation, we treated brain homogenates with increasing concentrations of calpain-1 and calpain-2. Calpain-2 produced a concentration-dependent reduction in PTEN levels in P2 membranes, whereas calpain-1 did not affect PTEN levels in the same concentration range (Fig. 7D). In contrast, calpain-1 caused a concentration-dependent reduction of both hamartin and tuberin (data not shown).

We further tested the effects of calpain-1 and calpain-2 on purified human PTEN. Coomassie blue staining detected a single band for PTEN under control conditions (absence of calpain) (Fig. 7E). Incubation of PTEN with calpain-1 plus calcium for $1 \mathrm{~h}$ at $37^{\circ} \mathrm{C}$ did not affect the levels of PTEN, although it shifted the band toward a slightly lower MW, suggesting that it may also cleave human PTEN at the very end of the protein sequence. In marked contrast, calpain-2 treatment strongly reduced the levels of full-length PTEN, and several breakdown products were detected at apparent MWs of 37, 23, 22 and $18 \mathrm{KDa}$, approximately, indicating the existence of several truncation sites within PTEN for this calpain isoform (Fig. 7E). The calpain cleavage site predictor tool suggests Thr319 and Tyr346 as the most probable truncation sites (both with a score of 0.13 ). Truncation at these sites would generate N-terminal fragments of 37.42 and 40.57 $\mathrm{KDa}$, respectively, probably corresponding to the highest and most intense of the bands observed. The remaining bands might result from further proteolysis of these $\mathrm{N}$-terminal fragments at Leu182 (score of 0.11 ), which would produce three breakdown products of $21.40,19.19$ and $16.03 \mathrm{KDa}$ that match the observed lower bands.

To determine whether there were any other targets of calpain upstream of PTEN, we used an antibody that preferentially recognizes proteins containing phospho-tyrosine at the consensus YXXM motif, such as receptor tyrosine kinases and adaptor proteins that recruit and activate PI3K. Treatment of acute hip- 
pocampal slices with BDNF or CX614 increased the levels of Tyr phosphorylation of a protein with an approximate MW of 110 $\mathrm{KDa}$, which most likely corresponds to GAB1 [GRB2 (growth factor receptor-bound protein 2)-associated binding protein 1], an adaptor protein involved in TrkB receptor signaling to PI3K. The effects of BDNF and CX614 on phospho-Tyr were not blocked by calpain inhibition, suggesting that PI3K activity is not affected by calpain (Fig. 8A). In addition, activation of TrkB receptor by BDNF and CX614 was unaltered by calpain inhibition in cortical synaptoneurosomes (Fig. 8B).

\section{Calpain-2 but not calpain-1 knockdown in cortical neurons blocks the effect of BDNF on mTOR activation}

Finally, we performed knockdown experiments to address which of the calpain isoforms were involved in BDNF-mediated mTOR activation. Thus, we transfected cortical neurons with siRNA against either calpain-1 or calpain-2, or with scrambled siRNA. Knockdown of calpain-1 did not prevent mTOR phosphorylation caused by BDNF or CX614, although there was a trend toward a reduction. In contrast, downregulation of calpain-2 completely blocked the effects of both BDNF and CX614 on mTOR activation (Fig. 9A). Transfection with siRNA for calpain-1 specifically reduced calpain-1, but not calpain-2, levels (Fig. 9B). Conversely, treatment with the siRNA for calpain-2 only affected calpain-2, but not calpain-1, protein levels (Fig. 9C).

\section{Discussion}

Our results indicate that calpain activation is necessary for BDNF-induced stimulation of the mTOR pathway and the subsequent increase in protein synthesis in hippocampal slices and cortical synaptoneurosomes, as calpain inhibition blocked BDNF-induced mTOR phosphorylation and Arc upregulation. Moreover, the effects were also reproduced in cultured cortical and hippocampal neurons, since calpain inhibitor III abrogated BDNF-stimulated increase in dendritic phospho-mTOR immunostaning, in PSD-95 synthesis and synthesis/maturation of myrGFP. In addition, we identified the molecular mechanisms by which BDNF stimulates the Akt-mTOR signaling pathway and enhances dendritic protein synthesis, which involves calpaindependent degradation of PTEN, hamartin, and tuberin. Figure 10 schematically represents the involvement of calpain in mTOR signaling pathway after TrkB receptor stimulation by BDNF. Our results clearly showed that calpain and calcium treatment decreases PTEN, hamartin, and tuberin levels in brain homogenates, indicating that these proteins are calpain substrates. Interestingly, our results also revealed a calpain isoform specificity for calpain-2 in the case of PTEN; to our knowledge, this type of isoform preference has not been documented previously. Hence, our studies provide strong evidence for a major role of calpain-2, compared with calpain-1, in BDNF-mediated synaptic plasticity, and this role was further confirmed with the results of the knockdown experiments with specific siRNA for the two main calpain isoforms in the brain. Also supporting this hypothesis, we reported previously that BDNF specifically activates calpain-2 but not calpain-1 within dendritic spines (Zadran et al., 2010), and a previous study indicated that in vivo calpain-2 gene silencing impairs LTP and learning and memory in mice (Zadran et al., 2012).

Over the last decades, the hippocampus has been shown to play a critical role in learning and memory for certain types of information (Jarrard, 1993). LTP is now widely recognized as a cellular mechanism of learning and memory, and current evi-
A
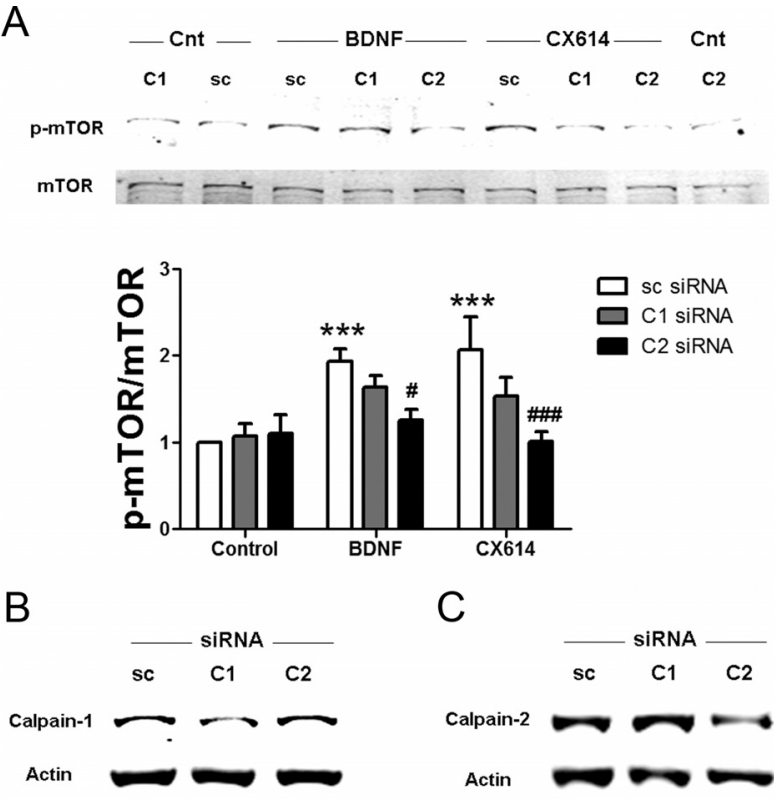

C
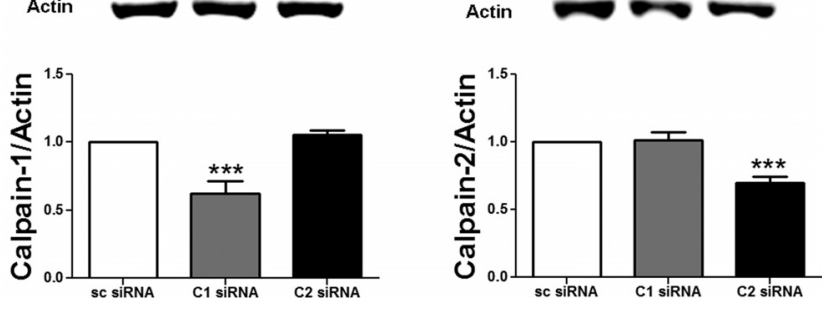

Figure 9. Knock-down of calpain-2 prevents BDNF-mediated mTOR phosphorylation. Primary cultured cortical neurons were transfected with scrambled siRNA (sc) or with siRNA for either calpain-1 (C1) or calpain-2 (C2) for $3 \mathrm{~h}$; $24 \mathrm{~h}$ later they were incubated with DMSO (Cnt) BDNF (100 ng/ml), or CX614 (50 $\mu \mathrm{m})$ for $30 \mathrm{~min}$. Cells were homogenized and processed for Western blot. $\boldsymbol{A}$, Data are presented as the ratio of phospho-mTOR over total mTOR (fold of control) and are means \pm SEM from six to seven independent experiments. ${ }^{* * *} p<0.001$ (compared to control); ${ }^{\#} p<0.05,{ }^{\# \# \# ~} p<0.001$ (compared to cells transfected with sc siRNA; two-way ANOVA). B, C, Data are presented as the ratio of calpain-1 or calpain-2 over actin (fold of control) and are means \pm SEM from five independent experiments. ${ }^{* *} p<0.001$ (compared to cells transfected with sc siRNA; one-way ANOVA followed by Dunnett's multiple comparison test).

dence suggests that LTP induction is followed by periods of consolidation during which protein synthesis is critically involved (Pfeiffer and Huber, 2006; Bramham, 2008; Sacktor, 2008). Exogenous BDNF application paired with weak burst stimulation induces robust LTP induction (Kovalchuk et al., 2002; Kramár et al., 2012) and facilitates LTP maintenance through activation of the PI3K-Akt-mTOR signaling pathway and regulation of local protein synthesis (Tang et al., 2002; Yang et al., 2008). BDNF rapidly induces Arc expression within minutes, an effect blocked by rapamycin, a specific inhibitor of mTOR, in neuronal cultures and in synaptoneurosomes and by the MAPK inhibitor U0126 in the dentate gyrus (Takei et al., 2004; Jourdi et al., 2009; Panja et al., 2009). In our study, activation of protein translation by BDNF in acute hippocampal slices involved both mTOR and MAPK signaling and was also completely suppressed by the protein synthesis inhibitor cycloheximide. Stimulation of Arc and $\alpha$ CaMKII synthesis was consistently reproduced in hippocampal slices, cortical synaptoneurosomes, and primary hippocampal and cortical neuronal cultures, either by exogenous application of BDNF or by stimulating the endogenous release of BDNF with the ampakine CX614 (Jourdi et al., 2009).

Calpains, a family of calcium-dependent proteases, have been shown to be involved in synaptic plasticity as well as in patholog- 
ical conditions (Lynch and Baudry, 1984; Vosler et al., 2008). Calpain activation has been observed following LTP induction (Vanderklish et al., 1995) and after BDNF application in cultured neurons and hippocampal slices (Shimizu et al., 2007; Zadran et al., 2010). Shimizu et al. (2007) found that a Ras inhibitor, suprachiasmatic nucleus circadian oscillatory protein (SCOP), was degraded by calpain following BDNF treatment of cultured neurons. Those results indicated that BDNF-induced calpain activation positively regulated the RAS-MEK-CREB signaling pathway and participated in hippocampusdependent learning tasks. However, under our experimental conditions, calpain inhibition did not block BDNF-mediated MAPK activation. The different timing of treatment may account for the differences between the two studies, since SCOP levels were rapidly decreased, but returned to basal levels within 30-60 min after BDNF stimulation (Shimizu et al., 2007). In addition, BDNF-mediated calpain-2 activation is triggered by ERK-dependent phosphorylation (Zadran et al., 2010), which suggests that MAPK activation induced by BDNF may be also upstream, and thus independent, of calpain activity. In any event, the existence of the calpain-SCOP-CREB cascade provides a plausible link between calpain activation and transcriptional regulation of genes that participate in synaptic plasticity and memory formation. Our results indicate that calpain is involved in synaptic plasticity and learning and memory through another signaling cascade, consisting of the regulation of local dendritic protein synthesis.

Acute blockade of PI3K was shown previously to impair LTP in hippocampal slices (Sanna et al., 2002; Tang et al., 2002; Cammalleri et al., 2003; Opazo et al., 2003). Our results indicate that calpain-2 cleaves PTEN, a phosphatase that inhibits Akt, and thus allows BDNF to trigger PI3K-Akt signaling. It was reported previously that calpain negatively regulates Akt activity through PI3K cleavage, under experimental conditions of serum starvation (Beltran et al., 2011). This study also showed that the association between calpain and PI3K was, however, reduced in the presence of serum. Together with our results, these studies indicate that calpain activity can bidirectionally regulate the PI $3 \mathrm{~K}-\mathrm{Akt}$ signaling pathway depending on the extracellular environment. The data presented here also suggest that Akt activation by BDNF leads to hamartin/ tuberin complex degradation, in which both calpain-1 and calpain-2 might be involved. This, in turn would relieve mTOR inhibition and facilitate local protein synthesis (Fig. 10). Overall, calpain activation seems to play complex and multiple roles in LTP induction and consolidation. In particular, it was proposed previously that initial calpain activation might be critical for the regulation of the actin cytoskeleton, which underlies the rapid enlargement of dendritic spines (Lynch et al., 2007; Rex et al., 2007; Zadran et al., 2010). In a second phase, we postulate that calpain activation, through PTEN, hamartin, and tuberin degradation relieves mTOR inhibition and stimulates protein synthesis, which might be critical for providing long-term consolidation of modified spine structures.

\section{BDNF}

TrkB receptor

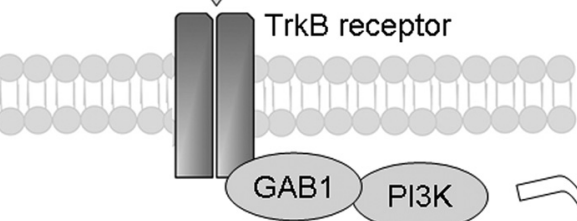

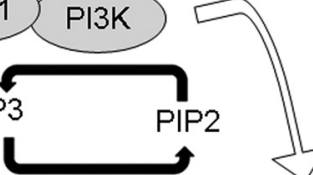
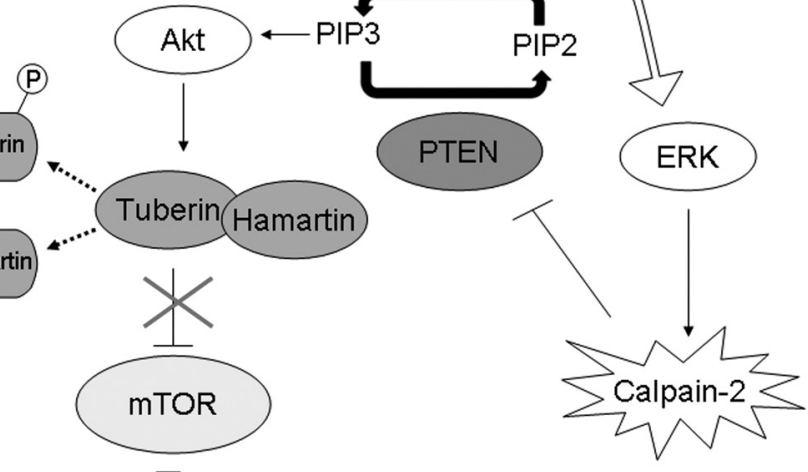

Dendritic protein synthesis

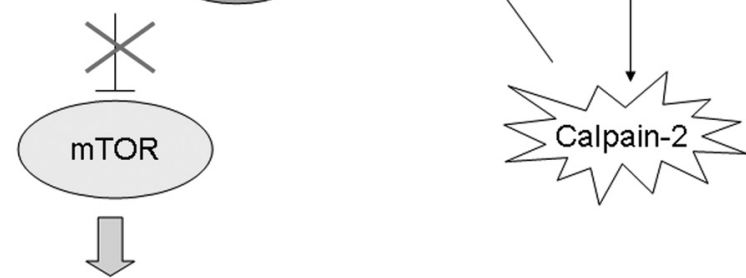
Figure 10. Schematic representation of the signaling pathways involved in calpain-mediated regulation of dendritic protein
synthesis induced by BDNF. Activation of TrkB receptor by BDNF results in PI3K activation and subsequent phosphorylation of Akt, leading to hamartin/tuberin complex dissociation and degradation by the proteosome (including calpain-1 and calpain-2). This in urn relieves mTOR inhibition and stimulates dendritic protein synthesis. In parallel, BDNF receptor activation results in ERK-

PTEN-deficient neurons exhibit decreased synaptic transmission and synaptic plasticity at hippocampal CA3-CA1 synapses. The different levels of PTEN in PTEN knock-out and PTEN heterozygous mice contribute to different effects on LTP (Fraser et al., 2008). Decreased PTEN expression results in increased dendritic branching in developing hippocampal neurons (Jaworski et al., 2005). However, little is known regarding the potential links between calpain and PTEN. One previous study has shown that calpain inhibitor I can block PTEN degradation and subsequent Akt activation after brain ischemia (Zhang et al., 2007). PTEN function is regulated by various posttranslational modifications, including phosphorylation, although the significance of these modifications is not completely clear at present (Barata, 2011). We did not detect a decrease in phospho-PTEN levels following BDNF treatment of hippocampal slices using an antibody recognizing phosphorylated Ser380/Thr382/Thr383. One possible explanation for this would be that calpain truncates PTEN after Thr383. Analysis of the amino acid sequence of PTEN in the C-terminal domain (which is the region recognized by the two PTEN antibodies used here) indicates that His397 could be a potential calpain truncation site. However, this is unlikely to account for all the observed effects involving calpain-2, as deletion of the last six amino acids (from Ser398) does not affect PTEN protein levels or its catalytic activity (Georgescu et al., 1999). Alternatively, it is possible that PTEN phosphorylation protects it from calpain-mediated truncation, as has been reported previously in nonneuronal cells (Torres and Pulido, 2001). Nevertheless, cleavage at His397 might be produced by calpain-1, as calpain-1 treatment of purified human PTEN caused a slight decrease in MW, although this did not happen with rat brain homogenates. Noteworthy is that residue Ser398 in rat corresponds to Thr398 in human, which may account for these differences. 
The use of the calpain cleavage site predictor tool provides two additional potential truncation sites for calpain-2 on PTEN, namely, Thr319 and Tyr346, with higher scores (both 0.13) than His397 (0.11). The resulting C-terminal fragments in all cases would have MW under $10 \mathrm{KDa}$, which may explain why they were not detected by Western blot. Instead, we were able to detect $\mathrm{N}$-terminal fragments of PTEN by Coomassie blue staining, which most likely correspond to those generated by truncation of PTEN at Leu182, Thr319, and/or Tyr346; these fragments would not be detected by Western blot because they would not express the epitopes recognized by the antibodies we used. Interestingly, a stop codon mutation at Thr319 was shown to destabilize PTEN and to suppress its phosphatase activity, and is the most frequent site mutated in different primary tumors (Georgescu et al., 1999 and references therein). Additional experiments will be directed at determining whether Thr319 and Tyr346 are actual phosphorylation sites that could affect the susceptibility of PTEN to calpain-2-mediated truncation.

Alterations in hamartin, tuberin, and PTEN, all regulators of mTOR-mediated signaling, have been implicated in autism spectrum disorder (Bourgeron, 2009; Ehninger and Silva, 2011). Interestingly, a link between calpain and hamartin and tuberin has been suggested previously (Benvenuto et al., 2000). Our results directly confirm this finding and moreover suggest that a similar link exists between calpain and PTEN. Hence, additional studies are needed to evaluate the potential involvement of calpain in autism spectrum disorder.

Overall, the present results improve our understanding of the mechanisms underlying BDNF effects in neuronal signaling and suggest that calpain activation is not only essential for LTP induction, but also plays a critical role in protein synthesis regulation. A similar idea regarding the role of protein homeostasis in synaptic plasticity was developed previously (Cajigas et al., 2010), and our results suggest that multiple mechanisms linking protein synthesis and turnover participate in this complex regulation.

\section{References}

Aakalu G, Smith WB, Nguyen N, Jiang C, Schuman EM (2001) Dynamic visualization of local protein synthesis in hippocampal neurons. Neuron 30:489-502. CrossRef Medline

Barata JT (2011) The impact of PTEN regulation by CK2 on PI3Kdependent signaling and leukemia cell survival. Adv Enzyme Regul 51:37-49. CrossRef Medline

Beltran L, Chaussade C, Vanhaesebroeck B, Cutillas PR (2011) Calpain interacts with class IA phosphoinositide 3-kinases regulating their stability and signaling activity. Proc Natl Acad Sci U S A 108:16217-16222. CrossRef Medline

Benvenuto G, Li S, Brown SJ, Braverman R, Vass WC, Cheadle JP, Halley DJ, Sampson JR, Wienecke R, DeClue JE (2000) The tuberous sclerosis-1 (TSC1) gene product hamartin suppresses cell growth and augments the expression of the TSC2 product tuberin by inhibiting its ubiquitination. Oncogene 19:6306-6316. CrossRef Medline

Bidinosti M, Ran I, Sanchez-Carbente MR, Martineau Y, Gingras AC, Gkogkas C, Raught B, Bramham CR, Sossin WS, Costa-Mattioli M, DesGroseillers L, Lacaille JC, Sonenberg N (2010) Postnatal deamidation of 4E-BP2 in brain enhances its association with raptor and alters kinetics of excitatory synaptic transmission. Mol Cell 37:797-808. CrossRef Medline

Bourgeron T (2009) A synaptic trek to autism. Curr Opin Neurobiol 19: 231-234. CrossRef Medline

Bramham CR (2007) Control of synaptic consolidation in the dentate gyrus: mechanisms, functions, and therapeutic implications. Prog Brain Res 163:453-471. CrossRef Medline

Bramham CR (2008) Local protein synthesis, actin dynamics, and LTP consolidation. Curr Opin Neurobiol 18:524-531. CrossRef Medline

Cajigas IJ, Will T, Schuman EM (2010) Protein homeostasis and synaptic plasticity. EMBO J 29:2746-2752. CrossRef Medline

Cammalleri M, Lütjens R, Berton F, King AR, Simpson C, Francesconi W,
Sanna PP (2003) Time-restricted role for dendritic activation of the mTOR-p70S6K pathway in the induction of late-phase long-term potentiation in the CA1. Proc Natl Acad Sci U S A 100:14368-14373. CrossRef Medline

Chen LY, Rex CS, Babayan AH, Kramár EA, Lynch G, Gall CM, Lauterborn JC (2010) Physiological activation of synaptic Rac $>$ PAK (p-21 activated kinase) signaling is defective in a mouse model of fragile $\mathrm{X}$ syndrome. J Neurosci 30:10977-10984. CrossRef Medline

Dominguez R, Liu R, Baudry M (2007) 17-Beta-estradiol-mediated activation of extracellular-signal regulated kinase, phosphatidylinositol 3-kinase/protein kinase B-Akt and N-methyl-D-aspartate receptor phosphorylation in cortical synaptoneurosomes. J Neurochem 101:232-240. CrossRef Medline

Ehninger D, Silva AJ (2011) Rapamycin for treating tuberous sclerosis and autism spectrum disorders. Trends Mol Med 17:78-87. CrossRef Medline

Fraser MM, Bayazitov IT, Zakharenko SS, Baker SJ (2008) Phosphatase and tensin homolog, deleted on chromosome 10 deficiency in brain causes defects in synaptic structure, transmission and plasticity, and myelination abnormalities. Neuroscience 151:476-488. CrossRef Medline

Georgescu MM, Kirsch KH, Akagi T, Shishido T, Hanafusa H (1999) The tumor-suppressor activity of PTEN is regulated by its carboxyl-terminal region. Proc Natl Acad Sci U S A 96:10182-10187. CrossRef Medline

Inoki K, Li Y, Zhu T, Wu J, Guan KL (2002) TSC2 is phosphorylated and inhibited by Akt and suppresses mTOR signalling. Nat Cell Biol 4:648 657. CrossRef Medline

Jarrard LE (1993) On the role of the hippocampus in learning and memory in the rat. Behav Neural Biol 60:9-26. CrossRef Medline

Jaworski J, Spangler S, Seeburg DP, Hoogenraad CC, Sheng M (2005) Control of dendritic arborization by the phosphoinositide-3'-kinase-Aktmammalian target of rapamycin pathway. J Neurosci 25:11300-11312. CrossRef Medline

Jourdi H, Hsu YT, Zhou M, Qin Q, Bi X, Baudry M (2009) Positive AMPA receptor modulation rapidly stimulates BDNF release and increases dendritic mRNA translation. J Neurosci 29:8688-8697. CrossRef Medline

Kelleher RJ 3rd, Govindarajan A, Jung HY, Kang H, Tonegawa S (2004) Translational control by MAPK signaling in long-term synaptic plasticity and memory. Cell 116:467-479. CrossRef Medline

Kovalchuk Y, Hanse E, Kafitz KW, Konnerth A (2002) Postsynaptic induction of BDNF-mediated long-term potentiation. Science 295:1729-1734. CrossRef Medline

Kramár EA, Chen LY, Lauterborn JC, Simmons DA, Gall CM, Lynch G (2012) BDNF upregulation rescues synaptic plasticity in middle-aged ovariectomized rats. Neurobiol Aging 33:708-719. Medline

Kumar V, Zhang MX, Swank MW, Kunz J, Wu GY (2005) Regulation of dendritic morphogenesis by Ras-PI3K-Akt-mTOR and Ras-MAPK signaling pathways. J Neurosci 25:11288-11299. CrossRef Medline

Lynch G, Baudry M (1984) The biochemistry of memory: a new and specific hypothesis. Science 224:1057-1063. CrossRef Medline

Lynch G, Baudry M (1987) Brain spectrin, calpain and long-term changes in synaptic efficacy. Brain Res Bull 18:809-815. CrossRef Medline

Lynch G, Rex CS, Gall CM (2007) LTP consolidation: substrates, explanatory power, and functional significance. Neuropharmacology 52:12-23. CrossRef Medline

Ma L, Chen Z, Erdjument-Bromage H, Tempst P, Pandolfi PP (2005) Phosphorylation and functional inactivation of TSC2 by Erk implications for tuberous sclerosis and cancer pathogenesis. Cell 121:179-193. CrossRef Medline

Oliver MW, Baudry M, Lynch G (1989) The protease inhibitor leupeptin interferes with the development of LTP in hippocampal slices. Brain Res 505:233-238. CrossRef Medline

Opazo P, Watabe AM, Grant SG, O’Dell TJ (2003) Phosphatidylinositol 3-kinase regulates the induction of long-term potentiation through extracellular signal-related kinase-independent mechanisms. J Neurosci 23: 3679-3688. Medline

Panja D, Dagyte G, Bidinosti M, Wibrand K, Kristiansen AM, Sonenberg N, Bramham CR (2009) Novel translational control in Arc-dependent long term potentiation consolidation in vivo. J Biol Chem 284:31498-31511. CrossRef Medline

Pfeiffer BE, Huber KM (2006) Current advances in local protein synthesis and synaptic plasticity. J Neurosci 26:7147-7150. CrossRef Medline

Qin Q, Liao G, Baudry M, Bi X (2010) Role of calpain-mediated p53 trun- 
cation in semaphorin 3A-induced axonal growth regulation. Proc Natl Acad Sci U S A 107:13883-71387. CrossRef Medline

Rex CS, Lin CY, Kramár EA, Chen LY, Gall CM, Lynch G (2007) Brainderived neurotrophic factor promotes long-term potentiation-related cytoskeletal changes in adult hippocampus. J Neurosci 27:3017-3029. CrossRef Medline

Sacktor TC (2008) PKMzeta, LTP maintenance, and the dynamic molecular biology of memory storage. Prog Bain Res 169:27-40. CrossRef

Sanna PP, Cammalleri M, Berton F, Simpson C, Lutjens R, Bloom FE, Francesconi W (2002) Phosphatidylinositol 3-kinase is required for the expression but not for the induction or the maintenance of long-term potentiation in the hippocampal CA1 region. J Neurosci 22:3359-3365. Medline

Shimizu K, Phan T, Mansuy IM, Storm DR (2007) Proteolytic degradation of SCOP in the hippocampus contributes to activation of MAP kinase and memory. Cell 128:1219-1229. CrossRef Medline

Staubli U, Larson J, Thibault O, Baudry M, Lynch G (1988) Chronic administration of a thiol-proteinase inhibitor blocks long-term potentiation of synaptic responses. Brain Res 444:153-158. CrossRef Medline

Takei N, Inamura N, Kawamura M, Namba H, Hara K, Yonezawa K, Nawa H (2004) Brain-derived neurotrophic factor induces mammalian target of rapamycin-dependent local activation of translation machinery and protein synthesis in neuronal dendrites. J Neurosci 24:9760-9769. CrossRef Medline

Tang SJ, Reis G, Kang H, Gingras AC, Sonenberg N, Schuman EM (2002) A rapamycin-sensitive signaling pathway contributes to long-term synaptic plasticity in the hippocampus. Proc Natl Acad Sci U S A 99:467-472. CrossRef Medline

Tee AR, Anjum R, Blenis J (2003) Inactivation of the tuberous sclerosis complex-1 and -2 gene products occurs by phosphoinositide 3-kinase/ Akt-dependent and -independent phosphorylation of tuberin. J Biol Chem 278:37288-37296. CrossRef Medline

Torres J, Pulido R (2001) The tumor suppressor PTEN is phosphorylated by the protein kinase $\mathrm{CK} 2$ at its $\mathrm{C}$ terminus. Implications for PTEN stability to proteasome-mediated degradation. J Biol Chem 276:993-998. CrossRef Medline

Vanderklish P, Saido TC, Gall C, Arai A, Lynch G (1995) Proteolysis of spectrin by calpain accompanies theta-burst stimulation in cultured hippocampal slices. Mol Brain Res 32:25-35. CrossRef Medline

Vanderklish P, Bednarski E, Lynch G (1996) Translational suppression of calpain blocks long-term potentiation. Learn Mem 3:209-217. CrossRef Medline

Vosler PS, Brennan CS, Chen J (2008) Calpain-mediated signaling mechanisms in neuronal injury and neurodegeneration. Mol Neurobiol 38:78-100. CrossRef Medline

Wells DG, Fallon JR (2000) Dendritic mRNA translation: deciphering the uncoded. Nat Neurosci 3:1062-1064. CrossRef Medline

Yang PC, Yang CH, Huang CC, Hsu KS (2008) Phosphatidylinositol 3 -kinase activation is required for stress protocol-induced modification of hippocampal synaptic plasticity. J Biol Chem 283:26312643. Medline

Zadran S, Jourdi H, Rostamiani K, Qin Q, Bi X, Baudry M (2010) Brain-derived neurotrophic factor and epidermal growth factor activate neuronal $\mathrm{m}$-calpain via mitogen-activated protein kinase-dependent phosphorylation. J Neurosci 30:1086-1095. CrossRef Medline

Zadran S, Akopian G, Zadran H, Walsh, Baudry M (2012) RVG-mediated calpain2 gene silencing in the brain impairs learning and memory. Neuromol Med. Advance online publication. Retrieved Aug. 21, 2012. DOI: 10.1007/s12017-012-8196-8. CrossRef

Zhang QG, Wu DN, Han D, Zhang GY (2007) Critical role of PTEN in the coupling between PI3K/Akt and JNK1/2 signaling in ischemic brain injury. FEBS Lett 581:495-505. CrossRef Medline

Zhou X, Lin DS, Zheng F, Sutton MA, Wang H (2010) Intracellular calcium and calmodulin link brain-derived neurotrophic factor to p70S6 kinase phosphorylation and dendritic protein synthesis. J Neurosci Res 88: 1420-1432. Medline 